\title{
Aa. Vv., Mémoires des chevaliers. Édition, diffusion et réception des romans de chevalerie $\mathrm{du} \mathrm{XVII}^{\mathrm{e}}$ au XX $\mathrm{XX}^{\mathrm{e}}$ siècle
}

\author{
Maria Colombo Timelli
}

\section{OpenEdition}

\section{Journals}

Édition électronique

URL : http://journals.openedition.org/studifrancesi/8826

DOI : 10.4000/studifrancesi.8826

ISSN : 2427-5856

Éditeur

Rosenberg \& Sellier

\section{Édition imprimée}

Date de publication : 1 octobre 2008

Pagination : $429-431$

ISSN : 0039-2944

\section{Référence électronique}

Maria Colombo Timelli, «Aa. Vv., Mémoires des chevaliers. Édition, diffusion et réception des romans de chevalerie du xvIl au xx siècle », Studi Francesi [En ligne], 155 (LII | II) | 2008, mis en ligne le 30 novembre 2015, consulté le 14 janvier 2021. URL : http://journals.openedition.org/studifrancesi/8826 ; DOI : https://doi.org/10.4000/studifrancesi.8826

Ce document a été généré automatiquement le 14 janvier 2021.

\section{(c) $)(1) \Theta$}

Studi Francesi è distribuita con Licenza Creative Commons Attribuzione - Non commerciale - Non opere derivate 4.0 Internazionale. 


\title{
Aa. Vv., Mémoires des chevaliers. Édition, diffusion et réception des romans de chevalerie du XVII ${ }^{\mathrm{e}}$ au XX siècle
}

\author{
Maria Colombo Timelli
}

\section{RÉFÉRENCE}

Mémoires des chevaliers. Édition, diffusion et réception des romans de chevalerie du XVII au XXe siècle, Paris, École des Chartes, 2007.

1 Ce beau volume réunit les Actes d'un colloque international co-organisé à Troyes fin 2005 par l'École des Chartes, la Médiathèque de l'Agglomération Troyenne (en la personne de son ancien directeur, Thierry Delcourt), l'Université de Reims (représentée par Danielle Quéruel, et non pas «Danièle Quervel», graphie qui apparaît dans les Remerciements, p. 9).

2 Françoise VIEILLARD, Qu'est-ce que le 'roman de chevalerie'? Préhistoire et histoire d'une formule, pp. 11-33. À partir du constat que le syntagme 'roman de chevalerie' est une création du $\mathrm{xVII}^{\mathrm{e}}$ siècle, F.V. rappelle rapidement heurs et malheurs du genre romanesque, objet tour à tour d'admiration et de condamnation, d'érudition et de divulgation, $\mathrm{du} \mathrm{XVI} \mathrm{I}^{\mathrm{e}}$ au début du XIX siècle.

3 Jean-Marc ChATELAIN, De l'errance à la hantise: la survivance des chevaliers aux xvii ${ }^{e}$ et xviii ${ }^{e}$ siècles, pp. 35-48. La collection de livres imprimés appartenus à Gaston d'Orléans (mort en 1660) et conservés à la Réserve de la BnF comprend un nombre significatif de textes médiévaux: chroniques, ouvrages destinés à l'instruction du prince, encyclopédies, pièces de théâtre, œuvres poétiques, et surtout romans de chevalerie. J.-M.Ch. souligne, d'une part, la formation d'un imaginaire médiéval, de l'autre les débuts d'un véritable esprit de 'collection' à l'âge classique. 
çoise GEVREY, Florian et les romans de chevalerie: du périodique au Novelliere, pp. 49-60. Il s'agit de deux récits d'inspiration médiévale, Bliombéris, chevalier de la Table ronde (publié en avril 1779 dans la «Bibliothèque Universelle des Romans») et Hermite et Arrodian, Anecdote du règne d'Artus (paru dans le «Mercure de France», février 1781). Transformés en nouvelles, ils furent encore publiés en 1784 en recueil et présentés, l'un comme nouvelle française, l'autre comme nouvelle portugaise. F.G. relève les changements de forme et de sens, en soulignant la transformation des récits en pastiches sur une toile de fond médiévale, témoignage de la culture et du goût de la seconde moitié du XVIII ${ }^{\mathrm{e}}$ siècle.

Pascale BolOGNINI-CENTÈNE, Madame Riccoboni et la transmission du roman de chevalerie à la fin $d u$ xviii $^{e}$ siècle, pp. 61-73. Sollicitée par Bastide et Tressan, Mme Riccoboni composa quatre nouvelles qui furent publiées dans la «Bibliothèque Universelle des Romans» entre avril 1779 et mars 1780: ce sont des récits brefs, situés dans un passé lointain, proches du genre troubadour. Cependant, le contexte historique demeure flou, et Mme Riccoboni, habile romancière, s'appuie plutôt sur quelques éléments descriptifs et stylistiques, sur une imagerie vague et composite, inspirée aussi à la pastorale et au roman noir.

Hélène BIU, Paulin Paris et la redécouverte de la littérature médiévale, pp. 75-90. H.B. resitue le père de Gaston Paris dans le contexte politique et culturel du XIx ${ }^{e}$ siècle, en soulignant son activité, sa méthode, les rapports parfois tendus avec d'autres savants de son temps, et surtout son rôle fondamental dans la mise en place des études de philologie romane en France.

7 Ursula BÄHLER, 'Chanson de geste' et 'roman courtois' ou le spectre de Gaston Paris, pp. 91-104. U.B. discute le classement générique adopté par Gaston Paris dès les débuts de sa carrière, l'idéologie sous-jacente et les différents regards que ce grand savant a portés sur la littérature médiévale. Elle conclut sur la signification du terme 'chevalier' qui, sous la plume de Gaston Paris, devient synonyme de 'courtois' et assume une coloration globalement négative, équivalant à 'conventionnel, artificiel'.

Nathalie CLOT, Georges-Adrien Crapelet et la «Collection des anciens monumens de l'histoire et de la langue françoise», pp. 105-118. Publiée entre 1826 et 1834, la Collection est née de l'initiative de Crapelet avec la collaboration de Dominique Méon, Conservateur adjoint aux Manuscrits de la Bibliothèque Royale. N.C. donne une liste commentée des douze volumes publiés, dans lesquels on trouve au moins quatre titres importants de la littérature médiévale: les Vers sur la mort, le Chastelain de Coucy, les poésies d'Eustache Deschamps, Partonopeus de Blois. Elle consacre ensuite quelques observations à la présentation matérielle de ces livres de luxe et à leur réception. Sans avoir vraiment influencé les romantiques de ces décennies, les Monumens ont néanmoins consacré la légitimité de l'édition des textes manuscrits.

9 Michel StAnesco, Moyen Âge vivant et conscience historique chez Louis de Marchangy, pp. 119-130. Personnage inconnu aujourd'hui, le juriste Marchangy (1782-1826) est l'auteur d'une Gaule poétique (8 volumes, 1813-1817), réévaluation du Moyen Âge à travers la poésie, et du Tristan voyageur (inachevé, 6 volumes, 1825-1826), prétendu 'tour de France' effectué en 1373. La redécouverte du passé médiéval, avec sa civilisation et ses traditions, sert à Marchangy - selon les mots de M.S. - «pour comprendre le présent et surtout le futur» (p. 130). 

avatars du 'Tristan' en prose, pp. 131-150. Le Tristan de Léonois d'Alfred Delvau (1859) s'inspire directement de la synthèse que le comte de Tressan avait publiée dans la Bibliothèque Universelle des Romans en avril 1776 (dérivée à son tour des rédactions en prose des $\mathrm{Xv}^{\mathrm{e}}-\mathrm{XVI} \mathrm{e}^{\mathrm{e}}$ siècles). Th.D. analyse suppressions, transformations et ajouts de Delvau, et souligne son recours fréquent aux dialogues, dont il offre des exemples représentatifs.

11 Philippe MÉNARD, L'écriture de Delvau, pp. 151-170. Ph.M. élargit l'analyse à trois adaptations de Delvau - Lancelot du Lac, Artus de Bretagne, Tristan de Léonois (1859) toutes basées sur les réfections de Tressan. Il souligne d'abord la «strate médiévale» qui concerne surtout le lexique, mais sans effet d'entassement: dans l'ensemble, en effet, vocabulaire, style et rhétorique demeurent classiques. Loin de souscrire au jugement sans appel prononcé par Léon Gautier, Ph.M. trouve que ces réécritures «constituent une étape intéressante dans la transmission des romans de la Table Ronde» (p. 170).

CORBELLARI, Le roman arthurien dans l'entre-deux guerres: de l'édition à l'adaptation, les chemins d'une réévaluation, pp. 170-185. Durant l'entre-deux guerres, la modestie de l'effort éditorial en France contraste avec les progrès de l'histoire littéraire; A.C. réfléchit sur les phénomènes marquants de ces décennies: réécritures de textes arthuriens par des adaptateurs indépendants du monde universitaire, vitalité de l'imaginaire médiéval chez quelques-uns des plus grands auteurs de l'époque (Cocteau, Breton, Éluard, Aragon...). Il se concentre ensuite sur André Mary, adaptateur de Chrétien de Troyes (Erec et Enide, Le Chevalier au lion, 1923), auquel il reconnaît quelques mérites littéraires et linguistiques.

L'entrée du roman de chevalerie dans le patrimoine littéraire de la jeunesse fait l'objet d'une étude en deux volets. Dans un premier article, Annie RENONCIAT (Tribulations de la chevalerie dans le livre et l'image pour la jeunesse. 1. Splendeurs et misères 1880-1939, pp. 187-203) rappelle les conditions de cette réappropriation à la fin du XIX $\mathrm{X}^{\mathrm{e}}$ siècle, les titres à succès (Quatre fils Aymon, Huon de Bordeaux, alors que le cycle arthurien est encore peu présent), les protagonistes du phénomène (auteurs, éditeurs, illustrateurs), et surtout les modalités d'adaptation (appareillage pédagogique, procédés de réécriture, récupération idéologique). Dans la seconde partie, cécile BOULAIRE (2. Disparitions, survies, trahisons dans la seconde moitié $d u \mathrm{xx}^{e}$ siècle, pp. 205-217) constate le renouvellement du corpus après la seconde guerre mondiale: il ne reste plus que quelques traces des Quatre fils Aymon sous la forme de contes, alors que revivent des personnages de la tradition arthurienne (le roi Arthur, Merlin, Lancelot). Avec les films ou les dessins animés, et avec le 'médiéval fantastique' dont Tolkien est le représentant le plus célèbre, le Moyen Âge est alors popularisé sous de nouvelles formes.

Jelle KOOPMANS ouvre des perspectives sur un domaine négligé par la recherche: la survie de la matière médiévale sur la scène (Quand les chevaliers se mettent à chanter: l'opéra devant la tradition narrative médiévale, pp. 219-229). Il s'agit d'une présentation critique, qui souligne d'une part la popularité de cette matière dans l'opéra, de l'autre la nécessité de rediscuter notre approche générique (notamment la distinction entre chanson de geste et roman) de la littérature médiévale.

Keith BUSBY et Françoise VIELLIARD (Conclusion, pp. 231-233) dressent un rapide bilan du colloque: ils mettent en relief le rôle joué par les intermédiaires qui, quels qu'aient été leur approche à l'ancienne littérature, le traitement qu'ils ont réservé aux textes 
médiévaux ou leur but immédiat, ont incontestablement concouru à entretenir la mémoire de la chevalerie jusqu'à nous. 